\section{La representación de "lo}

indígena" entre los viajeros

extranjeros en México,

1824-1867

\section{Rodolfo Ramírez Rodríguez ${ }^{1}$ rudolf_rrr@yahoo.com.mx}

The representation of "the indígena" among foreign travelers in Mexico, 1824-1867

\section{Resumen}

Este artículo pretende valorar la escritura de los viajeros extranjeros como una fuente histórica útil para estudiar el proceso de formación de lo mexicano. Las descripciones de los visitantes de los grupos indígenas del centro del país entre 1824 y 1867 proporcionan un fun- damento para reconstruir el carácter, las actitudes y la problemática social de los pueblos nativos, lo cual permite estudiar no solamente las trabas culturales para su desarrollo, sino también el proceso de conformación de una representación de lo ahora llamado nacional.

Palabras clave: representación, arquetipos, estereotipos, grupos indígenas, viajeros extranjeros.

\section{Abstract}

This article will try to evaluate the writing of foreign travelers as a useful historical source to study the process of the formation of the Mexican identity. Descriptions given by visitors to the indigenous groups in the centre of the country between 1824-
1867 provide a basis to reconstitute the character, attitude and social problems of the native groups which allows us to study not only the cultural impediments to their development, but also the process of the formation of a representation of what is now called "national".

Key words: representation, archetypes, stereotypes, indigenous groups, foreign travelers.

1 Universidad Nacional Autónoma de México, Facultad de Filosofía y Letras, México. Circuito de Posgrado, Ciudad Universitaria, Delegación Coyoacán, C. P. 04510, MéxiCO, D. F. 


\section{Introducción}

La visión de una cultura mexicana por parte de los viajeros extranjeros durante la primera mitad del siglo xIX forma parte del proceso de construcción de una concepción de lo mexicano en el orbe occidental, y me atrevería a sostener que incluso para la definición de aspectos de la cultura nacional entre los propios mexicanos. Estudiar el proceso por el cual se fueron conformando arquetipos y estereotipos de la cultura mexicana en representaciones literarias y pictóricas realizadas por una pléyade significativa de extranjeros venidos a la recién fundada República Mexicana nos brinda la posibilidad de rastrear la singular conformación de nuestros tipos populares, del enaltecimiento de nuestras costumbres, caracteres y formas de vida.

El redescubrimiento de este Nuevo Mundo luego de la visita de Alexander von Humboldt a principios del siglo XIX significó la posibilidad de realizar grandes empresas en los ámbitos comerciales de las naciones plenamente desarrolladas, como Inglaterra, Francia, los estados alemanes, y de los pujantes Estados Unidos de América. No obstante, para realizar sus viajes de exploración, explotación y hasta de posible invasión, los enviados (diplomáticos, militares, empresarios, aventureros y artistas) realizaron una importante labor de descripción y caracterización de lo que consideraban novedoso, a saber: los grupos sociales o étnicos encontrados, las costumbres alimenticias, festivas, laborales o religiosas y sobre todo la riqueza de los paisajes naturales encontrados en el camino a México (todo ello influido por los remanentes de la Ilustración y el apogeo literario del romanticismo). En esta literatura de viajes que incluye los escritos de los visitantes extranjeros (ya sean informes, descripciones, ensayos, diarios o cartas) se encuentra la formación de un imaginario compartido.

La tumultuosa primera mitad del siglo XIX es, sin duda, uno de los periodos más importantes en el surgimiento de la nacionalidad mexicana y en todos los ámbitos que componen al Estado moderno. Su construcción política, económica, social, cultural e ideológica fue el fundamento de lo que hoy se concibe como el pueblo y la nación de México. Sin embargo, este desarrollo se daría lentamente al paso de los años, con los encuentros y desencuentros de los nacidos en este país con los que no lo fueron: los "otros", los extranjeros. Este artículo abordará lo que significaron las primeras representaciones de los pueblos originarios en los testimonios escritos que dejaron dieciocho viajeros y analizará, grosso modo, las imágenes más características del ser "indígena" que se fueron conformando durante el periodo de 1824 a 1867, tras el encuentro con los nativos del 
centro del país (generalmente del grupo nahua) ${ }^{2}$ y la opinión surgida a raíz de esto. Esos testimonios de viajeros constituyen un referente creador de arquetipos y estereotipos sociales y culturales, y de lo que simbolizaba ese peculiar habitante que algunos viajeros consideraban "el verdadero mexicano".

Los viajeros de la primera parte del siglo XIX cumplieron una función importante a favor de la expansión de la modernidad a lo largo del orbe, pero especialmente en los territorios recién independizados de España que, como en el caso de México, se debatían en 1823 entre un imperio y el nacimiento de una república. La novedad de su aportación radica en que eran promotores de expresiones culturales muy distintas de las de México, como representantes de países en pleno desarrollo capitalista. Su contribución más importante fue la divulgación de sus impresiones de viaje en sus países de origen y su configuración de representaciones de costumbres, ambientes y actividades productivas que, a más de llamar la atención, podían ser utilizadas para los fines de la expansión del capital. Con ello se abrió paso a una serie de nuevas interacciones de toda índole que resultaran favorables a la expansión de las potencias en ciernes, aunque también servirían para que las naciones latinoamericanas, ${ }^{3}$ como nuestro país, recibieran la influencia cultural de la presencia de grupos extranjeros y asumieran con sentido crítico las descripciones que hacían los viajeros de un tema nacional, a veces con incomprensión y denostando las costumbres y el carácter del pueblo.

Es necesario presentar un breve balance historiográfico, si bien cabe señalar que, dado el carácter del artículo, se dejarán de lado muchas obras y estudiosos, por lo que vale decir que no están todos lo que son y no son todos los que están. El estudio de la literatura de viaje de los extranjeros en México surge a mediados del siglo xx con la publicación de tres obras generales: la primera de Jorge Silva, Viajeros franceses en México (1946), que es uno de los pocos estudios generales sobre visitantes extranjeros que produjeron obras numerosas en las cuales trataban de recrear lo mejor posible, en textos e imágenes, las singularidades de los pueblos. Iturriaga, Anecdotario, t. I, pp. 251-314; t. IV, 327-359; Ita Rubio y Sánchez, A través del espejo, pp. 357-436.

En este texto no se abordarán las representaciones de otros grupos indígenas como los del norte chichimeca, el occidente purépecha, el sur mixteco-zapoteco y el sureste maya del país, porque cada uno presenta una serie de peculiaridades (culturales, sociales, espaciales e históricas) que requieren un análisis más extenso que en este artículo no tiene cabida, pero que puede ser de interés para futuras investigaciones. En toda la América española y portuguesa se dio el mismo fenómeno de visitas de 
galos en nuestro país; luego está la obra de Juan Antonio Ortega y Medina, México en la conciencia anglosajona (1955), que brinda la entrada a los estudios sobre viajeros de procedencia anglosajona, y por último la de Margo Glantz, Viajes en México. Crónicas extranjeras (1964), una antología que rescata textos y que abre el interés por conocer el amplio ámbito de las descripciones del país por los forasteros. En cuanto a la impronta de Humboldt, se hicieron dos estudios: el de José Miranda, Humboldt y México (1962), que es un recuento de la concepción ilustrada que tenía la Nueva España hasta el momento de su llegada, y el de Ortega y Medina, Humboldt desde México (1964), que estudió la trascendencia del Ensayo político entre los pensadores mexicanos de 1821 a 1867.

Numerosas publicaciones de facsímiles, nuevas ediciones y rescates de obras de literatura viajera se han presentado desde 1970 hasta la fecha (en la colección SEP-Setentas, colección SEP-Ochentas, colección Mirada Viajera del Consejo Nacional para la Cultura y las Artes y la colección Viajeros del Banco de México), donde varios investigadores se encargaron de los prólogos, traducciones y estudios introductorios, como Lorenzo Ochoa, Martha Poblet, José Ortiz Monasterio, Margarita Carbó, Virginia Guedea, Ernesto de la Torre Villar, Clementina Díaz de Ovando, Elsa Cecilia Frost, Jacqueline Covo, etc. Hay que señalar que, además de dichas ediciones, se han publicado otras obras de viajeros en el Fondo de Cultura Económica, la Universidad Nacional, Miguel Ángel Porrúa y Porrúa Hermanos.

Pero a pesar de este gran esfuerzo editorial por dar a conocer numerosas obras de literatura de viajes en México, es significativo y revelador que existan pocos textos que aborden alguna temática en particular dentro de este corpus, sin exceptuar, claro está, las numerosas tesis universitarias que se han presentado sobre un proceso histórico o de interés en particular. Están los textos derivados de los congresos o coloquios que se han celebrado a partir del $v$ Centenario del descubrimiento de América, pero más allá de esto, los estudios temáticos no abundan y sólo algunos investigadores han cultivando este campo de la historiografía. Es importante resaltar el trabajo de Brígida von Mentz con su estudio sobre la percepción alemana del México decimonónico, México en el siglo XIX visto por los alemanes (1980), que se suma al artículo de Ortega y Medina, "La literatura viajera alemana del siglo xIX sobre México" (1962) y a su libro Zaguán abierto al México republicano (1987), que aborda las características e intereses de los viajeros ingleses y estadounidenses más sobresalientes durante las décadas de 1820 y 1830, entre otros estudios que realizó.

A nuestro juicio, tres obras se deben resaltar como un esfuerzo por adentrarse en la temática de lo indígena que representa una gran fuen- 
te de riqueza informativa que no ha sido desarrollada sino esporádicamente -el Anecdotario de viajeros extranjeros en México, Siglos XVI-XIX, en cuatro volúmenes, de José Iturriaga de la Fuente (1988-1992), es un compendio ilustrativo de ello-. La primera es la obra de Brigitte Boehm de Lameiras, Indios de México y viajeros extranjeros (1973), que intenta establecer una relación analítica entre los extranjeros y los grupos étnicos en el México decimonónico a través de las descripciones de éstos hechas por los primeros. La segunda es de José Enrique Covarrubias, Visión extranjera de México, 1840-1867. 1. El estudio de las costumbres y de la situación social (1998), cuya serie de estudios sobre seis viajeros radicados en el país muestra su percepción de la sociedad mexicana desde una base sociológica. El tercero es el libro coordinado por Manuel Ferrer Muñoz, La imagen del México decimonónico de los visitantes extranjeros: ¿un Estado-nación o un mosaico pluricultural? (2002), que rescata el tema de cómo fueron percibidas las sociedades indígenas por los viajeros extranjeros, si como raíz cultural del Estado mexicano, a pesar de su clara exclusión, o como obstáculo para el progreso nacional. Nuestro artículo pretende ser un estudio que completa esta temática: la conformación de una representación sociocultural de lo indígena por los extranjeros.

\section{Los viajeros: receptores de arquetipos y forjadores de estereotipos}

Antes de continuar trataremos de delimitar el concepto de viajeros. Estos visitantes, en su mayoría varones provenientes de las potencias de la época, representan un conjunto heterogéneo de personas que, por diferentes razones y circunstancias, llegaron a nuestro país con la finalidad de cumplir sus metas y satisfacer sus intereses respectivos. Sin embargo, en cada uno de ellos (y de ellas) encontramos la marca de la modernidad reinante en el mundo: apego al romanticismo subjetivo y al racionalismo, con visos del creciente capitalismo y mercantilismo característicos del siglo XIX. Por tanto el viajero era una persona rica, educada e ilustrada que recorría nuevos escenarios abiertos por la modernidad, que luego recreaba en su escritura (el diario de viajes) las impresiones y reflexiones sobre lugares y espacios ajenos, interesándose por las formas de vida social encontrada pero proyectando sus realidades particulares; reunía sus impresiones en un texto para ser publicado en su país de origen. ${ }^{4}$

4 $\quad$ Ramírez Rodríguez, Una mirada, p. Xv.

Letras Histórícas / Número 12 / Primavera-verano 2015 / México / pp. 9-11 / ISSN: 2007-1140 
Esta literatura nos introduce en el campo de las representaciones (entendidas como una construcción imaginaria y creativa de la realidad que hace visible las ideas abstractas), formadas a partir de un visor ajeno a través de sus observaciones de un país, necesarias para describirlo y divulgarlo en el mundo moderno. Así el viajero daría una serie de características a las culturas que encontraba en sus recorridos por el mundo (Asia, África, América y Oceanía), de manera que describía y clasificaba a la "otredad" y trataba de compartirla con su nación particular, que formaban parte del hemisferio occidental (industrializado, social y políticamente desarrollado). La fascinación que despertaba el relato de viajes, especialmente con respecto a las culturas lejanas, está marcada por la percepción de una alteridad cultural, social y política por parte de los viajeros. El relato de viajes se basa en testimonios de la memoria, a lo cual se achaca cierta subjetividad que, a la par, es evidencia de lo ocurrido, por lo que se tiene que considerar bajo diferentes dimensiones: ficcionalidad, intertextualidad, intratextualidad, sistemas de referencia y la obvia traducción, no sólo del traductor, sino del mismo autor en sus propias interpretaciones. ${ }^{5}$ Sin embargo, en la captación de lo que se presenta como culturalmente distinto se dan formas de percepción que a lo largo del tiempo dan origen a arquetipos y estereotipos.

El arquetipo es una representación o recreación del conocimiento de la realidad que predomina sobre las demás expresiones culturales y que se conforma en pautas de supremacía e influencia en el sistema del imaginario de una sociedad en particular; en otras palabras, el arquetipo es una imagen cultural que se convierte en un símbolo que constituye la base para la formación de una identidad propia. Pero si algunas de esas imágenes culturales son disociadas de su realidad o de su contexto y llegan a servir como identificadores de una sociedad determinada, por medio de la divulgación, se convierten en estereotipos. ${ }^{6}$ Esta tipificación cultural implica un conocimiento de la compleja estructura social, por lo que se debe resaltar la importancia de la relación entre el contenido de

5

por
Fontana, Europa; Pratt, Imperial; Serrano, "Viajes", y la obra teórica de Ette, Literatura. Consideramos las aportaciones de Said, Orientalismo, pp. 24-27, quien retoma el postulado de la "hegemonía cultural" de Antonio Gramsci en su estudio sobre la configuración del orientalismo en Occidente; Perkins, "Rethinking", que delimita el concepto de estereotipo como modelo de estudio de la ideología y producción cultural, y de F. Jameson, "Sobre los estudios culturales", que reconoce que la "tipificación cultural" de una sociedad por el visor ajeno implica un reconocimiento de facto. 
los estereotipos (atributos percibidos) y los arquetipos (atributos asumidos) de una sociedad, pues ambos "tipos" son definiciones culturales constituidas en un imaginario común y que ayudan a la comprensión de la socialización, ya que son "altamente efectivos, al proveer a la gente de explicaciones y definiciones de sí misma y de los demás", ${ }^{7}$ lo cual contribuye a la construcción de una imagen de una sociedad.

El estereotipo, entonces, es entendido como una imagen abstracta de la compleja dinámica de la historia y la sociedad de un grupo determinado, cuya eficacia simbólica, como parte de la cultura compartida, no puede negarse en la mente de propios y extraños. Para el caso que nos concierne, se inicia con la creación de arquetipos en los viajeros que tienen la posibilidad de "definir" a los grupos indígenas desde una óptica distinta, a través de atributos culturales, para conformar una imagen única que tiende a ser verídica por la cantidad y homogeneidad de las descripciones. Sin embargo, con la reiteración de esas descripciones se fue creando una serie de estereotipos usados en la literatura viajera. El estereotipo lo podemos entender como la representación divulgada: "Tanto en el vestir como en el comer, en las actividades productivas y sobre todo en las recreativas, que van adquiriendo sus especificidades, concentrando un determinado ser o deber ser que se conforma a través de la interacción de costumbres, tradiciones, historias, espacios geográficos, en fin: referencias compartidas y valoradas" en un mismo pueblo. ${ }^{8}$

Como escribió el primer historiador interesado en la literatura viajera del siglo XIX, Juan Antonio Ortega y Medina, en el caso de México, "aunque en un principio tierra virgen, el estereotipo preformado era fundamentalmente hispano, cargando sobre sí la tradición (condenación) histórica y española, imperial y católica". A ojos de los ajenos, tales imputaciones, tales estereotipos sociológicos, constituyeron una manera de dotarnos de ser, de concedernos existencia y de describir el ser mexicano. ${ }^{9}$ Aunque cabe aclarar que en cada uno de los viajeros se pueden hallar indicios de la filosofía y la sociología imperantes en sus naciones, que ponderaban los juicios sobre lo mexicano, podemos señalar que en la vertiente anglosajona la impronta de la moral del protestantismo, el progreso y la actividad comercial se halla mucho más presente en sus relaciones; en cambio, los franceses y germanos que pasaron más tiempo en México como inmigrantes aportan una representación menos prejuiciada y más apegada a la compleja realidad.

\footnotetext{
7 Perkins, "Rethinking", pp. 138-140, 147.

8 Pérez, Estampas, p. 131.

9 Ortega, México, p. 50.
} 


\section{El contacto de lo ajeno con lo propio}

Sabemos que describir es, necesariamente, un acto de restricción, pero a la vez de definición, de "dotarnos de ser", y la literatura de viaje es la herramienta de definición cultural por antonomasia. Así, un visor ajeno a la realidad mexicana pudiera describir objetivamente a un grupo con las características peculiares para conformar un arquetipo de "lo indígena", pero, al ser divulgado y repetido en numerosos medios, también corría el riesgo de convertirlo en estereotipo. Este problema inicial se puede resolver con la lectura cuidadosa de las diferentes capacidades de observación y análisis de los viajeros, pues habrá algunos que sólo expresan de forma estereotipada el "ser indio" y otros que harán un verdadero balance de síntesis y análisis que podrán ser calificados como reproductores y receptores de arquetipos culturales. ${ }^{10}$

El iniciador de esta serie de literatura viajera es sin duda Alexander von Humboldt, con su Ensayo político del Reino de la Nueva España, que es el primer estudio culto que nos lega un complejo conjunto de características de paisaje, clima y población de la Nueva España. ${ }^{11}$ Su finalidad era desmentir el argumento discriminatorio de las obras de varios filósofos europeos ilustrados que consideraban inferior la naturaleza y la sociedad americanas mediante un cúmulo de conocimientos científicos recabados en sus viajes por México y Sudamérica. Humboldt fue precursor de la idea de igualdad y de la interpretación liberal de la doctrina fisiocrática en boga, en contra del determinismo biológico.

Luego del periodo álgido de la lucha por la independencia y del infructuoso proyecto del primer Imperio Mexicano, presenciamos una primera oleada de viajeros anglosajones. La obra de Joel R. Poinsett, Notas sobre México. 1822, inauguraría la tradición de la literatura viajera en nuestro

Esta investigación no parte del estudio de la construcción de una idea de etnicidad entre las clases de intelectuales mexicanos, sino, como se verá, se enfoca en la percepción de los grupos sociales de la nación mexicana que se construirían en los viajes de algunos extranjeros por el México decimonónico. Nuestro objetivo es presentar las descripciones mejor logradas de los grupos indígenas del centro del país como referentes de todo México, así que dejaremos de lado las descripciones valiosas de importantes viajeros como Robert Willian Hale Hardy, John Lloyd Stephes, CharlesÉtienne Braseur de Bourbourg, Jean Luis Berlandier y Jean-Frédéric Waldeck. Ensayo político del Reino de la Nueva España forma parte de la obra Viaje a las regiones equinocciales del Nuevo Continente, publicada entre los años de 1799 y 1804, en la que resume temas de historia, geografía, botánica, biología y etnología de la realidad americana; Mentz, México en el siglo XIX, p. 27. 
país. Poinsett era agente especial de los Estados Unidos y su interés era conocer las regiones que México descuidaba, para obtener su anexión a su pujante nación. Con la República establecida llegan otros viajeros: William T. Penny, un mercader inglés que se dedicaría al pequeño comercio en las regiones del país y que escribió una serie de cartas de 1824 a 1826 donde relataba sus experiencias, reunidas bajo el título de Un bosquejo de las costumbres y sociedad de México; el empresario inglés George F. Lyon, quien vino comisionado para la explotación de minas adquiridas por compañías inglesas y estuvo en el país durante seis meses, consigna en su descripción de las zonas mineras aspectos sociales muy interesantes. Su obra se titula Residencia en México, 1826.

Siguiendo la posición europea de reconocimiento político de México y de expansión comercial e influencia ideológica encontramos al primer embajador del Reino Unido, Henry G. Ward, quien llegó al país con su familia con la intención de consolidar las relaciones diplomáticas con la Corona británica, de lo cual tenemos constancia en su obra México en $1827 .^{12}$

La mirada alemana está representada por Carl Koppe, nombrado primer cónsul general de Prusia en México y que se estableció como promotor comercial para los industriales alemanes en 1830. Su obra traducida lleva el título de Cartas a la patria. Otro visitante alemán es el comerciante hamburgués Carl Christian Becher, inspector de la Compañía Renana de las Indias Occidentales, cuya estancia en México, de 1832 a 1833, tenía la finalidad de incentivar las inversiones germanas, tal como lo expresa en sus Cartas desde México. Un alemán más fue Joseph Burkart, mineralogista que escribió Estancia y viajes en México en los años 1825 hasta 1834. Observaciones sobre el país, sus productos, la vida y costumbres de sus habitantes así como observaciones en la rama de mineralogía, geognosia, ciencia de minas, meteorología, geografía, fruto de diez años de viaje y exploración en minas mexicanas. ${ }^{13}$

De otro tipo de viajeros germanos que vinieron a tierras mexicanas con intereses muy diferentes del meramente lucrativo fue el hannoveriano Eduard Mühlenpfordt, considerado fundamental en la construcción de la idea que se tenía de México en el exterior, quien radicó en el país entre 1827 y 1835 trabajando como técnico en la construcción de caminos en Oaxaca. Durante su estancia realizó estudios de tipo geográfico y etnográfico que le sirvieron para publicar, en 1844, el Ensayo de una descripción de la República de México, sobre las características generales

12

13 (

Poinsett, Notas; Penny, en Ortega, Zaguán; Lyon, Residencia; y Ward, México en 1827.

Koppe, Cartas a la Patria; Becher, Cartas desde México; y Burkart en Mentz, México en el siglo XIX.

Letras Histórícas / Número 12 / Primavera-verano 2015 / México / pp. 9-11 / ISSN: 2007-1140 
del país y sus departamentos en la época centralista. Carl Bartholomäeus Heller fue un botánico austriaco que arribó en 1845, financiado por la Real Sociedad de Jardinería de Viena, y cuyo propósito era estudiar y recolectar especies nativas y enviarlas a Europa para su difusión. Su obra de carácter naturalista, Viajes por México en los años 1845-1848 (publicada en 1853), aborda el conflicto de la guerra de castas en Yucatán y la guerra contra los Estados Unidos.

En cuanto a los colonizadores que vinieron creyendo en la promesa de encontrar tierras para una explotación fácil y exitosa, aunque casi siempre frustrada, nos topamos con un caso interesante en la persona de Carl Christian Sartorius, alemán liberal de Hessen, que tuvo el sueño de hacer realidad una colonia utópica en tierras de Veracruz, pero al resultar ésta fallida decidió establecerse como propietario de una hacienda azucarera. Durante su larga estancia en el país, de 1826 a 1850, pudo conocer a fondo y escribir sobre las características geográficas del país y el carácter de su gente en México hacia 1850, obra fundamental para nuestro estudio. ${ }^{14}$

Volviendo a los viajeros anglosajones, en una época de consolidación de los arquetipos sociales hay dos obras dignas de resaltar por la buena narración y el análisis de las costumbres del México de mediados del siglo XIX. La primera es la de la esposa del primer embajador de España en México, Frances Erskine Inglis, marquesa de Calderón de la Barca: La vida en México durante una residencia de dos años en ese país (18391842), cuyas descripciones de la sociedad que encontró revelan el pensamiento mexicano decimonónico. La otra obra de reconocido mérito es la de Brantz Mayer, quien estuvo en México de 1841 a 1842 y cuyas agudas observaciones en cuanto a política, aspectos sociales e historia antigua de la nación mexicana quedaron plasmadas en México, lo que fue y lo que es. Ambos libros son importantes, pues contrastan el pensamiento anglosajón, liberal y protestante con las cualidades del carácter católico, conservador y apegado a sus costumbres de los mexicanos. ${ }^{15}$

Entre los viajeros franceses de mediados del siglo XIX encontramos una mayor heterogeneidad de intereses y escritos que van de las figuras enigmáticas del aventurero de Ernest de Vigneaux, que formó parte de la aventura del conde Gaston Raousset de Boulbon para independizar Sonora, quien registró en su diario las impresiones durante ese intento, su cautiverio por el gobierno de Santa Anna y su aprendizaje final de viajero al adoptar la postura de rechazar una abierta intervención militar en México, publicando su libro Viaje a México en 1853. Pasando por el interés

14 Mühlenpfordt, Ensayo; Heller, Viajes; y Sartorius, México hacia 1850.

15 Calderón de la Barca, La vida en México, y Mayer, México, lo que fue. 
naturalista del médico Lucien Biart, quien escribió su obra titulada La tierra templada. Escenas de la vida mexicana (1846-1855), adentrándose vivamente por las excursiones a parajes naturales y en las características de la sociedad mexicana, siendo a la vez representante del romanticismo y costumbrismo galo pero con una variedad de escritos de temas mexicanos. Y llegando al interés de los precursores de la arqueología e historia antigua de México, como Désiré de Charnay, quien fue uno de los primeros viajeros interesados por las culturas antiguas a las que relacionó con los grupos étnicos existentes del país. Su obra Ciudades y ruinas americanas es una amena narración de los aspectos culturales de la sociedad mexicana entre 1857 y $1861 .{ }^{16}$

Durante la intervención francesa en México y el Imperio de Maximiliano de Habsburgo encontramos algunas obras interesantes sobre el carácter y la cultura mexicanas. La primera es la de la condesa Paula Kolonitz, dama de compañía de la emperatriz Carlota, quien conocería el país y escribiría todo un conjunto de interesantes impresiones sobre los indígenas en su libro Un viaje a México en 1864. La segunda es el libro de un barón danés que formaba parte de los voluntarios austriacos y que vino a México de 1865 a 1867. Es uno de los escritos de viajes más agradables y esclarecedores de los aspectos sociales, culturales y populares inadvertidos por sus contemporáneos: Memorias de México, de Henrik von Eggers. Cabe también mencionar al oficial francés Éloi Lussan, quien publicó Souvenirs du Mexique como recuerdo de lo vivido durante la guerra de intervención, así como al teniente prusiano Carl von Gagern, quien luchó en el ejército mexicano durante la guerra de Reforma y la intervención francesa, y a quien por sus méritos militares le fue otorgada la nacionalidad mexicana. Fue miembro de la Sociedad de Geografía y Estadística, para la cual escribió en 1869 un artículo sobre los indígenas. ${ }^{17}$

\section{La problemática histórica y social del indígena}

Con la difusión del Ensayo de Humboldt, México pasaría de mero "hecho geográfico en la mente europea [...] a existir como un hecho cultural", lo que convirtió en realidad el sueño de ser partícipe del reconocimiento y posible desarrollo de las naciones libres. ${ }^{18}$ No obstante, en su obra percibió las graves problemáticas sociales de la Nueva España e hizo la crítica de la imperfección política del virreinato a lo largo de siglos y, por consi-

\footnotetext{
16 Vigneaux, Viaje; Biart, La Tierra, y Charnay, Ciudades.

17 Kolonitz, Un viaje; Eggers, Memorias; Lussan, Souvenirs, y Gagern, "Rasgos".

18 Moreno, "La ilustración", p. 78.
} 
guiente, de la extrema desigualdad que alentaba la inestabilidad entre los distintos grupos sociales que componían a la población:

Las diferencias de clase, rango y fortuna eran generales en todo el territorio del imperio; mas en ninguna parte eran tan acusadas como en la Nueva España, el país de la desigualdad en lo tocante a la distribución de las fortunas y en lo relativo a la civilización y al cultivo del suelo. ${ }^{19}$

Esta dura diferenciación y exclusión social, basada en lo racial, es el objeto de nuestro interés que resaltamos en los sucesivos textos.

Tras la independencia de México, los primeros viajeros en describir los cuadros populares fueron los anglosajones: los ingleses como William T. Penny, Georges Frances Lyon y el representante de la Corona británica, Henry George Ward, además del enviado plenipotenciario estadounidense Joel R. Poinsett. Todos ellos tenían una visión del indígena muy influida por la obra célebre de Humboldt, en la cual se había establecido que el grupo, o "la raza" indígena, se caracterizaba por un estado general de "indolencia y apatía" en sus actividades agrícolas y producciones manufactureras o artísticas, donde miseria y abandono enmarcaban una imagen que casi lo excluía del título de humanidad, pues se hallaba en él un "feliz embotamiento e insensibilidad"; sin embargo, exaltan su sinceridad, sencillez y buen temperamento, sobre todo el inglés Lyon. ${ }^{20}$

Estas observaciones se habían hecho sin mayor comprensión sobre la sociedad y la historia de México; serían los viajeros e inmigrantes alemanes de la década de 1830 quienes aportarían una descripción más aguda sobre el origen del estado de atraso de las comunidades indígenas. Opinaron que debido al largo periodo de dominio español, el reino de la Nueva España había sido dividido socialmente en segmentos de población diferenciados por el color de su piel (fenotipo), que solían coincidir con la actividad productiva que les fue asignada bajo el orden colonial, e incluso a esas categorías segmentadas racialmente-conocidas con el nombre de castas- se les imponía una definición asignada por su carácter moral y psicológico (arquetipo) que sería repetido ad infinitum por los viajeros, incluso después del establecimiento del orden republicano liberal.

De todos los viajeros alemanes, tal vez el que más acuciosamente inquirió sobre las características morales y sociales de los segmentos indígenas, dando origen a futuros estudios sociológicos, fue el ingeniero

19

20 Poinsett, Notas, p. 84; Penny, en Ortega, Zaguán, pp. 70-71; Lyon, Residencia, pp. 222225; y Ward, México en 1827, pp. 445-451. 
Eduard Mühlenpfordt, el primero que describió la taxonomía de las clases sociales en México (blancos, mestizos, mulatos, zambos, indios o cobrizos y negros africanos), siguiendo el esquema de grupos étnicos propio de Iberoamérica. Expresa que esta división "racial", típica del virreinato, tenía un doble fin ideológico-productivo:

Es sabido que en México, como en el resto de las posesiones hispanoamericanas, las diversas mezclas raciales tenían una gran importancia civil y política, además de la fisiológica, antes de la Independencia, y que por ello se les separaba rigurosamente. Al color blanco se le tenía por el más noble y digno. Conforme un individuo de sangre mezclada se acercaba más al blanco, en esa misma medida se le concedía reclamar derechos civiles más elevados. Por tanto, quien creyese llevar en la sangre un color más claro que el vecino, aunque fuese en mínima proporción, se preciaba de ser más noble y mejor que éste. ${ }^{21}$

Esta división netamente racista (y, en sus palabras, ridícula) desalentaba el mestizaje corriente debido a que "toda clase temía que su rango disminuyera mediante cualquier nexo con otra que estuviera más alejada que ella del blanco", ${ }^{22}$ lo cual no fue un impedimento capaz de resistir el proceso de integración de las diversas castas que, desde antes de la proclamación del acta de los Sentimientos de la Nación, comenzaban a diluir los límites cerrados del régimen virreinal. En sus descripciones, el autor muestra su agudo sentido de observación y la capacidad de emitir críticas sobre las condiciones observadas:

Los indios aparecen ante un observador superficial como una masa enorme y compacta, pero ésta se compone de numerosas ramas y subramas. Forman un número muy considerable de etnias diferentes, que sin embargo coinciden efectivamente en cuanto al color de la piel y otros caracteres, lo que parece indicar un origen común. Pero si se observan esas características detenidamente, se hallarán con facilidad diferencias y en muchos aspectos, como la lengua, costumbres, vestido o la misma constitución del cuerpo, las tribus se diferencian mucho entre sí. ${ }^{23}$

21

22 com

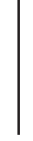

23

Mühlenpfordt, Ensayo, I, p. 168.

La idea de la superioridad del blanco se mantuvo durante el siglo XIX, pues era muy común oír que "no puede brindarse mayor alegría o mejor cumplido a las madres que la alabanza del blanco color de sus hijos", Mühlenpfordt, Ensayo, I, 170. Otras ideas con claro prejuicio cultural son expuestas por los alemanes Carl Becher y Karl Koppe.

Mühlenpfordt, Ensayo, I, p. 172. 
Como se puede observar, presenta pruebas concretas de la existencia de gran variedad de lenguas y de muchos más dialectos, que se habían formado lingüísticamente independientes, y nota variantes según su antigüedad, además de reconocer a las grandes familias de grupos étnicos, a los cuales menciona por sus nombres pero es capaz de sintetizar en un tipo fisonómico general del "indio" de México. ${ }^{24}$

Otro alemán, Joseph Burkart, presenta un balance de los indígenas respecto de los demás grupos sociales, pues a pesar de que la liberal constitución republicana de 1824 estipulaba que todos los mexicanos gozaban de los mismos derechos civiles -sin distinción de origen ni del color de piel-, se apreciaba mucho más el color blanco que "el cobrizo de los indios, o el negro y amarillo de los negros o mulatos". ${ }^{25}$

Carl Christian Sartorius, liberal, colonizador y posterior hacendado de Huatusco, Veracruz, ofrece una descripción realista de los grupos sociales que habitaban el país. Observa que en la sociedad mexicana existía un fuerte prejuicio por el color de la piel, a pesar de que las leyes no establecían distinciones de ninguna clase, al ser jurídicamente iguales todos los habitantes y al haberse anulado todos los privilegios de nacimiento y la esclavitud. Sin embargo, "las costumbres profundamente arraigadas entre la gente, y que son perpetuadas por el lenguaje, no pueden ser eliminadas fácilmente por ninguna ley: por consiguiente aquí encontramos una aristocracia de color", y el blanco es el detentador de ella. Le parecen absurdos y tristes estos prejuicios, pero comenta que para el observador de costumbres populares este aspecto es de sumo interés. A pesar de ello, reconoce en los grupos de la población mexicana pocos aspectos de unión, a excepción de los habituales y de un horizonte cultural compartido (religión, prácticas y aspectos festivos). Por su parte, los criollos, "apasionados y engreídos" dirigentes del país, y los mestizos en general, prototipos de los hábitos y peculiaridades nacionales, estaban abismalmente separados de los grupos originarios de México debido a su progreso social obtenido mediante la instrucción, los oficios y los trabajos que ejecutaban, que los diferenciaba de los indígenas, aunque también a éstos les daba el título de mexicanos. ${ }^{26}$

24

25 adoptadas por los mestizos de mejor posición económica; en cambio, entre los pobres la vida se asemejaba a la de los indígenas, por lo que el papel de los mestizos era de unificadores de dos razas: "un lazo por medio del cual la raza blanca se asemeja gradualmente a la morena". Sartorius, México hacia 1850, pp. 180-181 у 118. 


\section{El carácter de los pueblos indígenas}

En cuanto a los indígenas, "amos originales del suelo", Sartorius dice que son de "una sangre pura, originales en aspecto, vida y maneras" y aunque tienen una apariencia de tristeza, en realidad no hay "gente más alegre que estos indios cuando se juntan [...] Se muestran reservados con los criollos y mestizos, como si no tuvieran suficiente confianza con ellos; tampoco entienden su idioma lo suficiente para expresarse con fluidez", pues invariablemente emplean sus propias lenguas en sus negocios. El carácter de los nahuas con quienes trató era cerrado, desconfiado y calculador no sólo ante personas ajenas, sino dentro de la propia comunidad, pues: "el indio que desea obtener algo de otro nunca se lo pide directamente o sin rodeos: primero le hace un pequeño regalo, en seguida elogia esto o aquello, y al final formula su deseo". Dice que les gustaba hablar con ambigüedad, pues su mismo lenguaje abunda en expresiones ambiguas con el objeto de poder interpretar luego con ventaja para ellos todo cuanto se hubiere dicho. ${ }^{27}$

Mühlenpfordt describe al indígena como "generalmente serio, callado e incluso casi melancólico, mientras la música y la bebida embriagante no despierten su espíritu vital y lo vuelvan alegre y parlanchín", y adelante reflexiona sobre su carácter ("propio del pueblo mexicano"):

La poco común fuerza de carácter le permite guardar las pasiones, la cólera o el ímpetu de venganza durante mucho tiempo en lo profundo de su ser. Ninguna señal exterior delata el fuego que bulle en su interior, hasta que éste estalla con una violencia incontrolable.

Le gusta imprimir en su actuar una apariencia de secreto o importancia, habla enfáticamente cuando es necesario, y es muy rara la expresión de broma o la carcajada franca. ${ }^{28}$ También describe magistralmente la actitud indígena ante una actividad laboral pedida:

Como trabajador o criado, así como en cualquier negocio que con él se acuerde o trabajo que él mismo solicite, el indio demanda un trato enteramente suave y amistoso como condición para mostrar su confianza y realizar dócilmente lo que se le pide. Abordarlo con arrogancia o aires de importancia despierta su natural orgullo, y si se hace con dureza, su terquedad. Entonces se mostrará inflexible y renuente. Pero si se le trata con dulzura y se le pide el cumplimiento de sus obligaciones

\begin{tabular}{l|l}
27 & Sartorius, México hacia 1850, pp. 138, 140-141. \\
28 & $\begin{array}{l}\text { Mühlenpfordt, Ensayo, I, p. 192. }\end{array}$
\end{tabular}

Letras Histórícas / Número 12 / Primavera-verano 2015 / México / pp. 9-11 / ISSN: 2007-1140 
contraídas como si se tratara de favores, sin olvidar acercársele ocasionalmente en forma lisonjera, como iguales, para llamarle hermano y amigo y reprocharle sus faltas, negligencias o errores con seriedad y sin acaloramiento o dureza, entonces el indio abandonará pronto su desconfianza y lúgubre hermetismo, para volverse confiable y entregado. ${ }^{29}$

Ante las cualidades que presenta el vasto grupo indígena para el trabajo, sólo se requería saber cómo tratarlo. El autor reivindica la importancia social de los indígenas:

Son ellos quienes cultivan el campo y practican la cría de animales en su propio suelo; trabajan como jornaleros en las haciendas y ciudades; abastecen los mercados de urbes y pueblos con la verdura y la fruta de sus huertos, los productos de sus campos y los de su industria artesanal. También forman una gran parte de los trabajadores de minas y haciendas de beneficio; suyos son los oficios de albañil, carpintero, alfarero, carbonero, ladrillero, calero, fabricante de tejas y leñador... como sirvientes domésticos y también como soldados de la milicia y del ejército. ${ }^{30}$

Lo cual da a entender que, sin ellos, la producción nacional se paralizaría irremediablemente. En consecuencia, se debía promover su desarrollo social y la superación de la noción de "inactividad" debida a la "postración civil e intelectual" en que los españoles deliberadamente los sumieron. Concluye que los indígenas ocupaban el escalón inferior del desarrollo intelectual y social y lo que se había hecho por mejorarlos era bien poco. Esta deficiencia se podría corregir, argumenta Sartorius, si salieran más profesores de enseñanza elemental de las comunidades indígenas, "capaces de impartir los cursos en su propio idioma y a la vez enseñar la lengua española correctamente": una visión adelantada para su época y bastante optimista. Como sentencia Sartorius: son "un pueblo distinto dentro del mismo pueblo".

Mühlenpfordt reitera la necesidad de dar mejor educación a los indios para liberarlos de su "marasmo intelectual" producido por siglos de opresión, pues arguye que sólo cuando se les dieran mayores oportunidades Mühlenpfordt, Ensayo, I, p. 198.

Mühlenpfordt, Ensayo, I, pp. 193-194. Sin embargo, también aclara Mühlenpfordt que el rechazo de los trabajos pesados es una consecuencia histórico y no de simple apatía, ya que el sector indígena fue "despojado de sus derechos civiles durante todo el imperio español [y vio] fluir el fruto de sus esfuerzos y labor hacia las bolsas de sus dueños". 
y se abrieran las puertas para su formación intelectual, junto con una mayor cultura, podrían entonces conocer otras necesidades e intereses que ofrece la vida. ${ }^{31}$ Pero cuando las condiciones de la existencia cotidiana son adversas, en un estado de marginación, ignorancia y pobreza que fue frecuente para todo el siglo XIX, sólo se fomentarían los vicios sociales.

Escribió Mühlenpfordt que las comunidades indígenas tenían autonomía política: "aun en la actualidad se eligen los funcionarios municipales de los pueblos, alcaldes y auxiliares (topiles) entre los indios del lugar". Esa elección se hacía cada año entre las antiguas familias nobles o de caciques. Al referirse a los ancianos alcaldes de los pueblos, le sorprende la

seriedad, así como la tranquila y orgullosa dignidad con que esta gente desempeña su puesto de alcalde, [que] les confiere una apariencia realmente noble, incluso en asuntos de lo más intrascendente. Son auténticos regidores de sus pueblos, y sus órdenes e instrucciones casi siempre encuentran una obediencia incondicional. ${ }^{32}$

Sartorius postula la existencia de una gran desunión histórica entre las etnias, pero además señala que tenían un lastre por su estrecha relación con la dominación externa, pues recalca que, además de incultos y carentes de energía, los hombres estaban embrutecidos por la bebida y confinados al estrecho círculo de una existencia estereotipada y a un modo de pensar que no cambiaba desde hacía siglos. Este prejuicio se enfoca en la indolencia, que era uno de "los legados de su raza", pero que se había vuelto "más patéticamente ridículo" por su afición a las bebidas espirituosas y por las reglas establecidas de una religión que no eran capaces de entender. Un rasgo peculiar era su adicción "a sus viejas costumbres, dinero que ganan es dinero gastado en bebidas espirituosas en los días de fiesta, o bien enterrado para tenerlo seguro" ${ }^{33}$ Con motivo de su ancestral afición por el pulque, Sartorius presenta una valiosa reflexión sobre la cultura de los indígenas: "Sus costumbres tradicionales son estereotipos", refiriéndose a que sus producciones culturales se presentan como signos inalterables de su cultura a través del tiempo. ${ }^{34}$

\footnotetext{
31

32 enpfordt, Ensayo, I, p. 197. Estas comunidades administraban su dinero y la propiedad de sus tierras en común, sólo la casa habitación y un pequeño huerto eran heredables, a pesar de la influencia del peonaje en las fincas cercanas. Sartorius, México hacia 1850, p. 144.

33

34 Sartorius, México hacia 1850, pp. 82, 84.
} 
Algunas otras caracterizaciones de estereotipos indígenas las encontramos en su negación rotunda a nuevas prácticas y el apego a su concepción de tradición, pues se aferraban tenazmente a sus viejos usos, opiniones y costumbres. Eran "enemigos de toda innovación", debido a su desconfianza de cualquier institución o instrumento nuevo, máxime si provenía de los europeos:

Si uno se esfuerza por arrancar al indígena algún prejuicio arraigado o alguna opinión preconcebida, o bien en hacerle comprender la conveniencia de una nueva técnica o las ventajas de una nueva herramienta que hasta entonces desconocía, éste escuchará silenciosamente todos los argumentos del caso con un gesto serio, gran paciencia y aparente atención. Nunca rebate las razones esgrimidas, sino que tiende a mover pensativamente la cabeza y a murmurar de vez en cuando : "Sí, señor, tiene usted mucha razón", o "es verdad, señor". Finalmente, cuando uno cree haber alcanzado la meta, dados los aparentes signos de que está de acuerdo, y dirige al indio la pregunta definitiva, es decir, si ahora está convencido y quiere adoptar la nueva técnica o utilizar la nueva herramienta, la respuesta "usted tiene mucha razón, pero... nosotros no sabemos... no estamos impuestos a esto" demuestra lo infructuosos que han sido todos los esfuerzos de convencimiento. ${ }^{35}$

Otro ejemplo del apego a sus costumbres y de la incapacidad para favorecer un desarrollo económico capitalista era la inutilidad de las ganancias obtenidas en pago en metálico, que se solían enterrar en varias comarcas indígenas (como en la Mixteca y los valles de Toluca y Puebla). La economía de subsistencia del sector indígena se traducía en falta de interés por el ahorro y un casi nulo consumo de productos manufacturados, y mucho menor solicitud de servicios:

Un cobrizo común casi nunca se encamina a las ciudades o a los mercados de los pueblos y villas más grandes para comprar con efectivo lo que pudiera necesitar. Se aguanta con lo que compró la última vez hasta tener algo que llevar al mercado y cambiarlo por el dinero con que cubre sus necesidades [...] Nunca piensa en ahorrar o en las necesidades del mañana, de ahí que nunca tenga dinero y que en caso de necesitarlo por cualquier razón deba ganarlo siempre mediante el trabajo o la venta de productos. El tiempo y el esfuerzo (las bases del pensamiento capitalista) no forman parte de los cálculos de los indios

35 Mühlenpfordt, Ensayo, I, pp. 197-198. 
cuando se dirigen al mercado. Sus costos de viaje casi no superan los del sustento de la casa. Lleva consigo tortillas, sal y chile, y por unos cuantos centavos paga en las chozas de sus congéneres una tacita de atole por las mañanas, y un plato de frijoles por las noches. ${ }^{36}$

Así, en aquella época la transacción económica predominante entre la población indígena era el trueque. Asimismo, los indígenas aprovechaban un nimio comercio durante sus viajes al transportar de un pueblo a otro barro vidriado, esteras o sombreros, con los cuales pagaban su manutención y obtenían ganancias.

En estas circunstancias, el francés Ernest de Vigneaux, hacia 1853, trata de comprender la situación de la población más numerosa y pobre del país, a la cual parece aceptar y con la cual incluso parece simpatizar, aunque no deja de criticarla:

El pobre indio ha sido desde siglos tan explotado, se ha abusado de tal modo de su ingenuidad y buena fe de todos sus sentimientos, en fin, que la inferioridad e ignorancia en que le ha dejado la vida no puede pintarse sino con los más feos colores. ${ }^{37}$

Una observación notable que hace es que, en su viaje, cuanto más se acercaba a la ciudad de México (o a cualquier otra ciudad importante del país) existía mayor menosprecio de la raza conquistada y mayor era la soberbia de los conquistadores; partía del supuesto de que mientras más cerca se encontraran los indígenas del centro de poder, menor era su contacto con la civilización, lo que desembocaba en un rechazo social y en la pérdida de sus costumbres. ${ }^{38}$ Esta descripción de los indígenas sería recurrente entre los viajeros franceses llegados en las décadas de 1840 y 1850 (un preámbulo discursivo de la posterior intervención francesa), quienes retomaron el argumento de que la debilidad y la corrupción del Estado mexicano había incidido en el retroceso y la degradación de las grandes capas sociales representadas por los grupos indígenas.

\section{Las expresiones culturales de lo indígena}

Mühlenpfordt halla cualidades esenciales en la familia indígena (seriedad y hermetismo), unidad en el matrimonio, el amor de los padres por los

\footnotetext{
36 Mühlenpfordt, Ensayo, I, p. 200.

37 Vigneaux, Viaje, p. 44.

38 Vigneaux, Viaje, p. 80.
} 
hijos y la gran influencia de la mujer en el aspecto económico del hogar, además del respeto por los demás seres de la naturaleza con quienes convivían los indígenas. ${ }^{39} \mathrm{El}$ botánico austriaco Carl Bartholomäeus Heller ofrece atinadas observaciones culturales de los indígenas; así, dice por ejemplo que aunque las mujeres desempeñan un papel subordinado en esta sociedad, son "las que mantienen los antiguos usos y costumbres", pues "una vez que han alcanzado cierta edad, empiezan a tener una gran influencia en su comunidad"; toman entonces el lugar del médico y se convierten en profetisas, y gozan del respeto de los jóvenes en los rituales, pues éstos oyen con reverencia las palabras de las mujeres y los ancianos. ${ }^{40}$ La mujer hace la parte más pesada del trabajo (comida, cuidado de los niños, vestido de la familia y lavado de ropa) por la cual nada recibe, y es abnegada y comprensiva. La comida de los indios es simple, a excepción de la festiva (el mole, los tamales y demás platillos), y la medicina tradicional es sencilla pero eficaz, con el uso de la herbolaria, el temazcalli y el servicio de las mujeres como curanderas. ${ }^{41}$

Carl Heller señala la buena recepción que se daba al viajero hasta en el más pequeño rancho indígena, con tanta bondad y amabilidad que "uno se sorprende de que gente que vive en una pobreza tan grande [...] pueda tener un ánimo tan amistoso y tan recto", y adelante enuncia que "el mexicano más pobre abre amablemente su choza a quien se lo pide". ${ }^{42}$ Este mismo rasgo social (relación entre pobreza y amabilidad) lo subraya el médico y escritor francés Lucien Biart, por el estado de pobreza aparente en el indígena así como entre los sectores mestizos, habitual en las poblaciones mexicanas. Biart decía "aparente" porque

la miseria real y degradante, tal como se encuentra tan a menudo en la envidiada Europa, no existe en México. El hambre, ese terrible enemigo del pobre en las grandes ciudades del viejo mundo, es un espectro ignorado bajo un clima en que los árboles dan más frutos que los que una población puede consumir. ${ }^{43}$

Sin embargo, a pesar de la admiración que se expresa, la visión de los indígenas es agria, pues, según el alemán Carl C. Becher, "estos indios

39 Mühlenpfordt, Ensayo, I, pp. 198-200. Asimismo, encuentra Sartorius una gran sensibilidad por la naturaleza.

40

41

42

43 Heller, Viajes, p. 83. Sartorius, México hacia 1850, pp. 148-155. Heller, Viajes, pp. 96, 102. Biart, La Tierra, p. 103. 
siguen siendo una raza peculiar de hombres, a la cual sólo difícil y lentamente (nunca en resumidas cuentas) se la deja elevarse al grado de cultura y conocimiento en el que se hallan nuestros aldeanos [de Alemania]", pues ni siquiera se les apartó de su paganismo. ${ }^{44}$ La crítica a una religiosidad que consideran híbrida del catolicismo popular con las creencias de sus antiguas divinidades es contundente en todos los viajeros, sobre todo los estadounidenses, aunque muchos lograron advertir la grandeza de la fe de los más desamparados.

Ernest de Vigneaux describe los santuarios de la Virgen de Guadalupe, patrona de México, y de la Virgen de los Remedios, patrona de los españoles, aunque dice satíricamente que existe un número infinito de Vírgenes milagrosas y que cada pueblo tiene la suya; no obstante, estas dos advocaciones son las más celebradas por multitudes de indígenas que acuden a los santuarios en sus "trajes tradicionales y coronados de flores". ${ }^{45} \mathrm{En}$ el del Tepeyac, el arqueólogo francés Desiré Charnay señala la capilla del Pocito, donde "cada día, el indio crédulo viene a renovar su provisión agotada, a recitar humildes plegarias a los pies de la Virgen y regresa satisfecho de haber podido contemplar un instante la imagen divina", ${ }^{46}$ pero critica el negocio que hacía con ello el clero. Por su parte, el estadounidense Brantz Mayer declara al presenciar la fiesta de la Virgen de los Remedios: es una celebración "auténticamente indígena", que sin embargo se confunde con una "fiesta del maíz", la cual no es más que una acción de gracias por las cosechas recibidas, pues es un sustituto de los sacrificios a su diosa Centeotl, ante lo que no puede dejar de criticar: "La culpa la tienen quienes permiten estos ritos idolátricos delante de la imagen falsificada de otra imagen", una clara crítica de su protestantismo ante ese catolicismo mexicano, "mezcla de ritos de muchas naciones" que no considera ningún mal mientras se ofrezcan al Dios verdadero y universal. ${ }^{47}$

Heller hace un relato minucioso al describir una festividad religiosa cuando habla del "baile de Moctezuma" interpretado en una comunidad veracruzana y da su opinión: de "esta manera se celebran en México las conmemoraciones de los grandes momentos de la religión católica (pensé para mis adentros), mientras observaba sorprendido las locas vueltas de estos indios", lo que le convenció de la existencia de "una mezcla de idolatría" con los usos religiosos católicos como medio de atracción de nuevos feligreses, por lo que considera que después de 300 años los pue-

\begin{tabular}{l|l}
${ }_{44}$ & Becher, Cartas sobre México, p. 78. \\
45 & Vigneaux, Viaje, pp. 58, 80-81. \\
${ }_{46}$ & Charnay, Ciudades, pp. 72-73. \\
${ }_{47}$ & Mayer, México, lo que fue, pp. 190-194.
\end{tabular}

Letras Históricas / Número 12 / Primavera-verano 2015 / México / pp. 9-11 / ISSN: 2007-1140 
blos indios entienden tan poco de la religión como antes de la conquista. Termina expresando una fuerte censura: "En vez de ídolos heredados de sus padres se les dieron nuevas imágenes sagradas talladas en madera, sin enseñarles a conocer al verdadero Dios", pues afirma que "siguen aún presos de infinidad de prejuicios y errores y aun cuando crean en Dios, en quien veneran sólo al buen espíritu, ponen todavía junto a él a su viejo dios que representa el principio del mal, que temen más que a cualquier cosa". ${ }^{48}$

La fiesta que presenció el alemán Becher fue la de la Virgen del Carmen en San Ángel, cerca de la ciudad de México. Creía que sería sólo una celebración religiosa, pero su impresión fue muy grande cuando en la procesión de imágenes que salió del templo vio muestras de sincretismo que catalogó de paganismo, ante la complacencia de los sacerdotes, y fue mayor su asombro al observar que "le ofrecían a la tierra bolitas de alimento y a Vizlipuzli [sic. por Huitzilopochtli] los antiguos sacrificios y conjuros, cortando ahora el aire con sus largos cuchillos". Lo que lo lleva a exclamar con visión puritana: "¡y pensar, no obstante, que todo aquel completo cortejo estaba bajo la dirección de los eclesiásticos católicos, y que había salido y regresaba a un templo cristiano!" 49

Por su parte, en sus andanzas por la sierra, Lucien Biart describe con minuciosidad el desfile popular de la fiesta del pueblo de Tilapa, Veracruz, dedicada a su santo patrono, con músicos tocando, cantando o haciendo cualquier otro ruido inimaginable. Proporciona una interesante narración de la danza de Santiago y la de Hernán Cortés y la Malinche..$^{50}$ Pero al reflexionar sobre este tipo de celebraciones catárticas, Biart se pregunta juiciosamente sobre el recuerdo del pasado nativo entre los indígenas:

quedé persuadido de que los indios, lo mismo en la tierra templada que en la caliente, han olvidado su historia. ¿No es extraño verlos resucitar en sus propias fiestas a los personajes que derribaron a Moctezuma y celebrar de ese modo la gloria de los conquistadores? Esas mascaradas, que con algunas variantes se repiten en todos los pueblos, tienen incontestablemente origen azteca. Desde los primeros días de la conquista, los misioneros españoles reemplazaron sin duda a un ídolo indio con la imagen de Santiago y dieron lugar a una fiesta a que los indios no se atrevieron a quitar las apariencias de ceremonia católica. ${ }^{51}$

\footnotetext{
48 Heller, Viajes, pp. 76-77, 83.

49 Becher, Cartas sobre México, p. 122.

50 Biart, La Tierra, pp. 171, 175.

51 Biart, La Tierra, pp. 180-181.
} 
Como se ha visto, en todos estos comentarios sobre la religión popular indígena se presenta una perspectiva que nos recuerda los posteriores estudios de Max Weber de la ética protestante y de la sociología de la religión, que se contraponen con la cultura católica, donde la religión cristiana, mezclada con el pensamiento y los cultos antiguos, permitía que el indígena adoptase el catolicismo "más [como] un velo cómodo bajo el cual ocultar sus antiguas creencias idólatras. La Trinidad cristiana, sus numerosas Vírgenes María y la multitud de santos y de santas le presentan fáciles analogías con sus dioses, vencidos pero no muertos". ${ }^{52}$ Estas palabras son del prusiano Carl von Gagern, quien extendía tal opinión a todas las etnias de México, a las que también acusó de degeneración de su cultura. Esa condición sólo reiteraba el abandono intelectual y mental en que se encontraban los indígenas por siglos de explotación de sus diferentes gobiernos (virreinal, imperial o republicano). La única ocasión de catarsis social era en las celebraciones, donde tomaban parte diferentes grupos sociales y la estratificación se disolvía, pues en un día de fiesta o Carnaval ${ }^{53}$ la interacción social se daba plena y se podía creer que lo que unía a los diversos tipos de mexicanos era su tradición festiva.

\section{Lo indígena como raíz de la cultura mexicana}

Sobre el grupo indígena como fundamento de lo mexicano, la escocesa Frances Erskine Inglis, la mujer del primer embajador español en México, Ángel Calderón de la Barca, enunciaba en 1841 la siguiente consideración: desde el momento de la conquista todo el sector cayó en un "estado de ignorancia y degradación del que no han salido nunca". Ésta fue una de las ideas promotoras del estereotipo del indio "agachado o sedente", así como de una imagen de aceptada humillación y abnegado desamparo. ${ }^{54}$ Eduard Mühlenpfordt criticó asimismo el status del indígena hacia 1843, cuando afirmaba que "en una época en la que el indio no ha recobrado más que la mitad, cuando mucho, de sus derechos humanos", tiene muy pocas posibilidades de educación intelectual o espiritual. Y añade sobre la inutilidad de la aportación europea: "tanto la llegada de la encarecida civilización europea como de la religión católica le han sido hasta ahora de escaso provecho, y apenas se percibe, dondequiera que sea, algún indicio de que haya avances hacia el mejoramiento

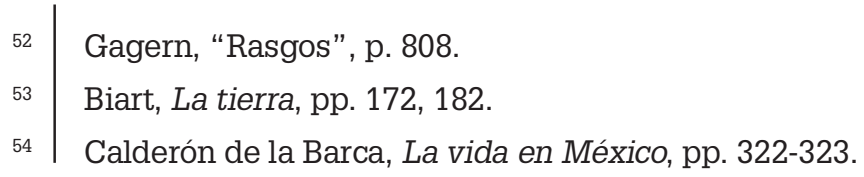


de su situación", lo que muestra sensibilidad del autor ante la realidad de sometimiento indígena. ${ }^{55}$

Carl von Gagern, quien radicaría en el país durante los años de 1853 a 1871, escribió diversas opiniones sobre los indígenas; creyó encontrar el origen de su aislamiento en su naturaleza "antisocial", pues prefería "la última miseria, con tal de sufrirla solo en su choza, a todas las comodidades que pueda brindarle la sociedad". Por tanto, exhortaba a que se introdujeran mejoras para que el indígena pudiera ingresar al mundo civilizado: "es preciso cambiar esos entes sociales en miembros útiles, productivos y progresivos de la sociedad; en una palabra, es necesario regenerar la raza indígena". La supuesta melancolía la atribuía a un vago presentimiento de la fatalidad, pero el principal obstáculo que encontraba eran sus usos y hábitos, pues como expresa, "la tenacidad con que los indios están apegados á sus costumbres es extraordinaria". ${ }^{56}$

Por ejemplo, en cuanto a la "apatía" mostrada por los indígenas en cuestión de política Gagern la achacaba a que siempre habían sido traicionados en movimientos de esa índole por los dirigentes criollos, de manera que su imperturbabilidad se justificaba por la carencia de una meta que alcanzar, y eso explicaba, según él, su estoicismo y su falta de temor ante la muerte, pues "¿por qué temerla cuando la vida no le ofrece ningún goce?" 57 Algunos periodistas alemanes darían su opinión sobre los indígenas inmersos en la guerra de la Intervención y en el segundo Imperio:

Los indios parecen estar, en general, de acuerdo con el nuevo estado de cosas; los pobres no entienden nada de principios políticos y tampoco desean saber nada. Esto ya se manifestó con hechos durante toda la guerra civil [de Reforma], en la cual no sirvieron más que como cubierta para satisfacer intereses personales, que utilizaron y siguen utilizando. Lo que quieren los indios es calma y orden; que se les libere de las enormes cargas y del servicio militar obligatorio; el que los emancipe de todo esto, ése es su amigo. ${ }^{58}$

Para los viajeros austriacos venidos con el Segundo Imperio, que acusan la influencia romántica del historicismo de Johann G. Herder, los

55
56
57
58 Mühlenpfordt, Ensayo, I, p. 185.

Gagern, "Rasgos", pp. 808, 812, 815-818.

Gagern, "Rasgos", pp. 807-808.

"La situación de México", Allgemeine Zeitung, núm. 321, Augsburg, 17 de noviembre de 1863; en Monjarás, México en 1863, p. 108. 
mexicanos eran los habitantes no indios, mestizos en mayor o menor grado, que no sabían gobernarse solos y causantes de la triste condición de los nativos. Una visión representativa es la de Paula Kolonitz, condesa austriaca que fungió como dama de la emperatriz Carlota. A su juicio, la decadencia socio-racial del indígena se debía a la prepotencia criolla, a la subyugación económica y a las reglas impuestas por el liberalismo mexicano, que ocasionaba la resignada destrucción y el cambio de su cultura, por lo que asevera que "la verdadera protección no ha existido nunca":

Hay en la naturaleza del indio americano algo de inquieto, de angustioso y de meditabundo. Instintivamente se recoge en sí mismo como si quisiera huir al contacto de la mano extranjera, aunque sea la mano que lo llama con las formas de la civilización, bajo cuyo peso parece que se ha aniquilado y se extingue. En su andar triste, en los melancólicos y dulces trazos de su fisonomía, fuerza es reconocer el carácter infeliz de una nación que fue dominada.

La causa de la humanidad ha ganado grandemente, viven bajo el amparo de una legislación mejor [la de 1857], gozan de mayor seguridad, su fe es más pura; pero todo esto de nada sirve. Su civilización lleva en sí la señal de la soledad del Nuevo Mundo; las ásperas virtudes de los aztecas fueron las bases fundamentales de su existencia y ellas se opusieron a la cultura europea como para no dejar injertarse por una rama extraña. ${ }^{59}$

Aquí curiosamente se muestra un interesante origen del incipiente nacionalismo mexicano que, paradójicamente, es extraído de las raíces de las comunidades indígenas: de su autonomía, de su orgullo y valentía, y de la fortaleza ante la adversidad, cualidades luego del pueblo mexicano. Sin embargo, en términos llanos, la situación de los indígenas en ese momento era muy precaria, su actuación era vilipendiada y su presencia repudiada por la elite, pero, por otra parte, era necesaria para los regímenes en combate, por ser ellos campesinos y militares:

esta pobre gente, a la que se ha mantenido en su abyección, sin embargo ha derramado su sangre para sustraer al país del dominio tiránico de los españoles [...] ¿Qué han ganado ellos? Desde entonces, en su nueva calidad de ciudadanos, están obligados al servicio militar, y eso es todo. En todos los demás aspectos, su condición social sigue siendo aquella que determinaron las viejas ordenanzas españolas, y

59 Kolonitz, Un viaje, p. 118. 
después como antes, ahora como hace cien años [...] el europeo o el descendiente de europeo sigue siendo el amo para ellos [...] Merecerían mejor suerte. ${ }^{60}$

Éstas son palabras del oficial francés Éloi Lussan acerca de la situación social de los pueblos que habían entregado vidas en los numerosos ejércitos que combatieron en las anteriores guerras civiles e invasiones sólo por la trágica leva que se ensañaba con los campesinos y los sectores urbanos más desfavorecidos. Éste fue un tema común en toda la literatura viajera del siglo.

No obstante, las virtudes físicas e intelectuales de los indígenas, su buena disposición, su impresionante tenacidad y entrega al trabajo, además de su honradez y lealtad en cargos militares - "siempre que se les sepa tratar con justicia y ganar su confianza" - hacían que se les considerara "trabajadores valiosos y soldados valientes y constantes, apegados a sus comandantes". ${ }^{61}$ Kolonitz agregaría que "el abandono, el descuido, los malos tratos de tantos siglos habían paralizado y debilitado, quizá para toda la vida, las facultades intelectuales de aquel pobre pueblo".62 La visión imperial austriaca es entonces "antimexicana" pues, a su juicio, los gobiernos anteriores causaron la opresión, la ignominia y la degeneración del indígena.

El barón danés Henrik Eggers, militar del cuerpo austriaco de voluntarios, con un espíritu de aventura y una capacidad descriptiva y analítica sorprendente, también reflexionaría sobre la realidad indígena durante los años difíciles de la intervención. Apunta sagazmente que, a pesar de la heterogeneidad cultural entre los grupos, había una uniformidad en cuanto a su carácter, defectos y virtudes, pero siempre en una postura de aislamiento y desconfianza ante el fuereño:

Sus puntos de vista y sus formas de pensar y de proceder son comunes en atención a que durante los 300 años del dominio español se sometió a toda la raza nativa a la misma presión espiritual y física. Esa presión forjó en el indio un carácter sumiso y desconfiado que no ha podido ser erradicado durante el corto tiempo en que el país ha disfrutado de libertad y seguramente tendrán que transcurrir muchos años para que pueda ser extirpado. ${ }^{63}$

\footnotetext{
60 Lussan, Souvenirs, pp. 227-228. Lussan, Souvenirs, p. 275. Kolonitz, Un viaje, pp. 158-159.

63 Eggers, Memorias, pp. 193-194.
} 
Esta forma de conducta social se debía a un "miedo ancestral al desconocido". No obstante que su inteligencia se enfrentaba a fuertes trabas sociales, había grandes esperanzas, pues aunque eran pocos los que habían logrado superar su tradicional posición subordinada y abrirse camino en los puestos del clero y de los profesionales en el gobierno, esto demostraba la fehaciente capacidad del indígena para absorber la cultura moderna. ${ }^{64}$ Por otra parte, Eggers explica la nula participación política del indígena porque delegaba en otros los derechos y obligaciones que tenía por ley: "poco participa en la vida pública del país, y como ciudadano se limita a reclamar sus derechos a través del alcalde". En cuanto a sus virtudes, lo que más admira es el estoicismo con que soporta el sufrimiento ante el dolor y la muerte, e intenta explicar plausiblemente el origen de ello: "Posiblemente esta actitud se deriva de una cierta indiferencia al destino; es una especie de fatalismo que también muestra cuando sufre una enfermedad o se accidenta"; ${ }^{65}$ resalta que para su curación y alimentación es autosuficiente, por lo que era realmente valioso como soldado.

Al terminar la guerra contra la intervención francesa, Eggers pronosticó que, con la intensificación de la lucha, varios grupos, entre ellos los indígenas y mestizos, tomarían conciencia de su papel y apoyarían al bando republicano, y con el futuro proceso de secularización del país se aprovecharía el talento natural de todas las clases sociales, tanto altas como bajas, por lo que la educación del pueblo tendría un papel importante en el progreso social y a la vez como raíz del patriotismo y del orgullo nacional. Con ello se sentarían las bases para un nuevo periodo en la historia del país con un nuevo orden institucional, que tendría como desenlace una nueva gran revolución social para los grupos indígenas al iniciar el siglo $\mathrm{xx}$, al ser incorporados como base de un movimiento de nacionalismo promovido por un régimen que intentó modernizar el país.

\footnotetext{
64 Lo único que le hacía falta era el aprendizaje necesario para poder colocarse al mismo nivel cultural del europeo, pues había muchos casos de indios puros convertidos en los hombres más ilustres de México como testimonio de ello Eggers se refiere obviamente al presidente Benito Juárez y quizás al general republicano Porfirio Díaz. El indio tiene energía y firmeza de carácter y no había duda de que una vez que la difusión de la educación permitiera su elevación, él será quien conduciría a México a un futuro mejor. Eggers, Memorias, p. 194.

65 Eggers, Memorias, pp. 185, 197-198, 201 y 226.
} 


\section{Conclusiones}

Hemos realizado un recorrido por algunas visiones extranjeras de los grupos indígenas, de sus características sociales, sus costumbres, su tipo de pensamiento y su valor como origen de un patriotismo mexicano, durante el periodo que va de la consumación de la independencia a la victoria del gobierno republicano. Es un primer antecedente de la importancia social que tenían para México. Lo sorprendente de este recorrido es que, a pesar de encontrar algunas diferencias de visión sobre el ser indígena (sobre todo en el tema de si eran o no los "verdaderos mexicanos"), hallamos una sólida contribución de arquetipos y estereotipos que brindan las representaciones de "lo indio" entre todos los viajeros.

En primera instancia, como vimos en el apartado sobre la problemática histórica y social del indígena, el origen de la representación de lo indígena surgía de las categorías impuestas por el orden colonial, que a su vez se basaban en la tipificación del fenotipo con una fuerte correlación moral, lo que no pudo cambiar a pesar de las legislaciones liberales republicanas. Es más, la difusión de la imagen de lo indígena que realizó Humboldt ayudó a la conformación de las primeras imágenes estereotipadas, de manera que al arribo de los primeros viajeros de origen anglosajón y germano se fueron reproduciendo imágenes que no ayudaban a una cabal comprensión de la problemática histórica de los integrantes de los pueblos originarios de México, que sufrían un gran abandono. No obstante, con la llegada de una nueva generación de extranjeros, cuyo perfil más se asemejaba al de los inmigrantes europeos, encontramos a alemanes liberales como Eduard Mühlenpfordt y Carl Cristian Sartorius, quienes con su larga permanencia en el país pudieron establecer una representación de los arquetipos más acabada y apegada a la realidad de los grupos indígenas con quienes convivieron durante su estadía. Así, en el apartado sobre el carácter de los pueblos indígenas se muestra una reivindicación de lo indígena, e incluso se llegó a considerar a los autóctonos como los "verdaderos mexicanos", sin que ello impidiera mostrar tanto sus vicios como sus virtudes, pero atribuyéndoles una importancia capital en la economía nacional.

Con el paso del tiempo, lo que en un principio pareció ser la gestación de una serie de arquetipos culturales reflejada en las actividades, costumbres y carácter de los indígenas se convirtió pronto en una serie de estereotipos, consolidados en su mayoría por una nueva oleada de viajeros anglosajones como la señora Calderón de la Barca y Brantz Mayer, por germanos como Carl Heller y Carl Becher o franceses como Lucien Biart o Désiré Charnay, quienes a pesar de su interés por entender a la 
sociedad mexicana (como se ve en el apartado sobre las expresiones culturales de lo indígena), chocaban con una total incomprensión por su mentalidad a veces protestante, pero siempre inmersa en una moral racional, el interés por el progreso del liberalismo y la crítica por la extraña religiosidad sincrética de las creencias prehispánicas y el catolicismo popular hispano. A sus ojos se presentaba una serie de expresiones de lo indígena que podían ser muy reacias al cambio propuesto por los tiempos modernos y que era necesario remediar, aunque fuese con la imposición de un gobierno.

Por último, en el cuarto apartado, titulado "Lo indígena como raíz de la cultura mexicana", se muestra que, paradójicamente, los aspectos que habían caracterizado negativamente a los pueblos indígenas (como el rechazo al forastero, la tenacidad, el estoicismo, la valentía y el orgullo), que habían sido una respuesta frente a su status marginal en la sociedad mexicana, más tarde, en un sistema de gobierno impuesto por extranjeros, fueron el origen de una recuperación de lo mexicano, que fue exaltado luego en la lucha contra la Intervención francesa y el Segundo Imperio. Al finalizar la aventura europea se estaba gestando la valoración de los arquetipos sociales en la cultura nacional como una respuesta interna a las respresentaciones hechas por los extranjeros, con lo que resalta así que la descripción de "lo indio" fue un aspecto medular en la concepción de una imagen más realista e incluyente de los grupos originarios del país.

Podemos, pues, afirmar que los visitantes extranjeros aportaron una nueva dimensión: el análisis social del grupo desfavorecido de los indígenas. En este sentido sus observaciones sobre la conformación de los grupos sociales nos brindan una valiosa información para entender estos aspectos culturales, lo que hace importante el estudio, el análisis y la divulgación de las narraciones de esta literatura, escrita como a través de un espejo.

\section{Bibliografía}

Biart, Lucien

La Tierra templada, escenas de la vida mexicana, 1846-1855, México, Jus, 1959.

Becher, C.C.

Cartas sobre México. La República mexicana durante los años decisivos de 1832 y 1833, México, Universidad Nacional Autónoma de MéxiCo, 1959.

Calderón de la Barca, Madame

La vida en México durante una residencia de dos años en ese país (1839-1842), México, Porrúa, 2003. 
Covarrubias, José Enrique

Visión extranjera de México, 1840-1867. I. El estudio de las costumbres y de la situación social, México, Universidad Nacional Autónoma de México, Instituto de Investigaciones Dr. José María Luis Mora, 1998.

Charnay, Désiré

Ciudades y ruinas americanas, México, Universidad Nacional Autónoma de México, 1994.

Eggers, Henrik

Memorias de México, México, Miguel Ángel Porrúa, Cámara de Diputados, 2005.

Ette, Ottmar

Literatura de viaje, de Humboldt a Baudrillard, México, Universidad Nacional Autónoma de México-Facultad de Filosofía y Letras, 2001.

Ferrer Muñoz, Manuel (coord.)

La imagen del México decimonónico de los visitantes extranjeros: ¿un Estado-Nación o un mosaico pluricultural?, México, Universidad Nacional Autónoma de México-Instituto de Investigaciones Jurídicas, 2002.

Fontana, Josep

Europa ante el espejo, Barcelona, Crítica, 2000.

Gagern, Carlos de

"Rasgos característicos de la raza indígena de México", Boletín de la Sociedad Mexicana de Geografía y Estadística, México, Segunda época, t. I, 1869.

Glantz, Margo (traducción e introducción)

Viajes en México, crónicas extranjeras, México, Secretaría de Obras Públicas, 1964.

Heller, Carl Bartholomeüs

Viajes por México en los años 1845-1848, México, Banco de México, 1987.

Ita Rubio, Loudes de y Gerardo Sánchez Díaz (coord.)

A través del espejo: viajes, viajeros y la construcción de la alteridad en América Latina, Morelia, Universidad Michoacana de San Nicolás de Hidalgo-Instituto de Investigaciones Históricas, 2005.

Iturriaga de la Fuente, José

Anecdotario de viajeros extranjeros en México, siglos XVI-XIX (vol. I y IV), México, Fondo de Cultura Económica, 1988-1992.

Jameson, Fredric

"Sobre los estudios culturales", Beatriz González Stephan (comp.), Cultura y Tercer mundo. 1. Cambios en el saber académico, Caracas, Nueva Sociedad, 1996.

Kolonitz, Paula

Un viaje a México en 1864, México, Secretaría de Educación Pública, 1976. 
Koppe, Carl

Cartas a la Patria. Dos cartas alemanas sobre el México de 1830 (traducción, estudio preliminar y notas de Juan A. Ortega y Medina), México, Universidad Nacional Autónoma de México-Facultad de Filosofía y Letras, 1955.

Löwenster, Isidore

México. Memorias de un viajero, México, Fondo de Cultura Económica, 2012.

Lussan, Éloi

Souvenirs du Mexique, París, Plon, 1908.

Lyon, Georges Francis

Residencia en México, 1826. Diario de una gira con estancia en la República de México, México, Fondo de Cultura Económica, 1984.

Mayer, Brantz

México, lo que fue y lo que es, México, Fondo de Cultura Económica, 1953.

Mentz, Brígida von

México en el siglo XIX visto por los alemanes, México, Universidad Nacional Autónoma de México, 1980.

Miranda, José

Humboldt y México, México, Universidad Nacional Autónoma de México, 1962.

Monjarás Ruiz, Jesús

México en 1863, testimonios germanos sobre la intervención francesa, México, Instituto Nacional de Antropología e Historia, 1988.

Moreno, Rafael

"La ilustración mexicana que encontró Humboldt", Leopoldo Zea y Mario Magallón (comp.), Humboldt en México, México, Universidad Nacional Autónoma de México, Programa Universitario de Difusión de Estudios Latinoamericanos, Instituto Panamericano de Geografía e Historia, Fondo de Cultura Económica (col. Latinoamérica-Fin de Milenio, núm. 13), 1999, pp. 67-81.

Mühlenpfordt, Eduard

Ensayo de una fiel descripción de la República de México, referido especialmente a su geografía, etnografía y estadística, t. I. México, Banco de México, 1993.

Ortega y Medina, Juan Antonio

"El Ensayo Político de Humboldt", Leopoldo Zea y Mario Magallón (comp.), La huella de Humboldt, México, Universidad Nacional Autónoma de México, Programa Universitario de Difusión de Estudios Lati- 
noamericanos, Instituto Panamericano de Geografía e Historia, Fondo de Cultura Económica (col. Latinoamérica, Fin de Milenio, núm. 14), 2000.

Ortega y Medina, Juan Antonio

México en la conciencia anglosajona, II. México, Antigua Librería de Robredo, 1955.

Ortega y Medina, Juan Antonio

Zaguán abierto al México republicano (1820-1830), México, Universidad Nacional Autónoma de México, 1987.

Pérez Monfort, Ricardo

Estampas de nacionalismo popular. Ensayos sobre cultura popular y nacionalismo, México, Centro de Investigaciones y Estudios Superiores en Antropología Social, 1994.

Perkins, Teresa E.

"Rethinking stereotypes", Ideology and cultural production, Nueva York, Saint Martin's Press, 1979.

Poinsett, Joel Roberts

Notas sobre México 1822, México, Jus, 1973.

Pratt, Mary Louise

Imperial Eyes: Travel Writing and Transculturation, Londres y Nueva York, Routledge, 1992.

Ramírez Rodríguez, Rodolfo

Una mirada cautivada. La nación mexicana vista por los viajeros extranjeros, 1824-1874, tesis de maestría en historia, Universidad Nacional Autónoma de México, Facultad de Filosofía y Letras, 2010.

Said, Eduard W.

Orientalismo, Madrid, Debate, 2002.

Sartorius, Carl Christian

México hacia 1850, México, Consejo Nacional para la Cultura y las Artes, 1990.

Serrano, María del Mar

"Viajes y viajeros por la España del siglo XIX", Cuadernos críticos de geografía humana, Universidad de Barcelona, año XVII, núm. 98 (septiembre de 1993).

Silva, Jorge

Viajeros franceses en México, México, América, 1946.

Vigneaux, Ernest de

Viaje a México, México, Fondo de Cultura Económica, Secretaría de Educación Pública, 1982.

Ward, Henry George

México en 1827, México, Fondo de Cultura Económica, 1995.

Recibido: 26/03/2014. Aceptado: 08/11/2014 